\title{
Empleo doméstico y violencia laboral. Notas críticas desde una posición sociojurídica feminista
}

\author{
Domestic Employment and Labor Violence. Critical Notes from a Feminist \\ Legal Point of View \\ Emprego doméstico e violência laboral. Notas críticas desde uma posição \\ sócio jurídica feminista
}

ROMINA LERUSSI

FECHA DE RECEPCIÓN: 29 DE DICIEMBRE DE 2015. FECHA DE ACEPTACIÓN: 19 DE ABRIL DE 2016

DOI: DX.DOI.ORG/10.12804/ESJ 18.02.2016.05

Para citar este artículo: Lerussi, R. (2016). Empleo doméstico y violencia laboral. Notas críticas desde una posición sociojurídica feminista. Estudios Socio-Jurídicos, 18(2), 147-174. Doi: dx.doi.org/10.12804/esj 18.02.2016.05

\section{RESUMEN}

El 13 de marzo de 2013 fue aprobado en Argentina el Régimen especial de contrato de trabajo para el personal de casas particulares. Esta norma derogó el Decreto-ley 326/1956, el cual fue sancionado en un contexto de dictadura militar y reguló por más de cincuenta años al sector doméstico en unas condiciones que han sido calificadas no solo de discriminatorias, sino inconstitucionales. Situadas en el pensamiento jurídico feminista crítico, la hipótesis general que sostenemos es que, a pesar de contar con una nueva regulación, los problemas asociados con modalidades de violencia laboral estructural tales como las exclusiones, desigualdades y la invisibilización e infravaloración históricas dadas a este sector laboral feminizado no se resuelven solo con una nueva ley (que, no obstante, celebramos), sino con disrupciones y desplazamientos radicales en las interpretaciones de lo que la dogmática entiende por su naturaleza jurídica. Con esta hipótesis, en el presente texto nos abocamos a una de las tres notas definitorias de la naturaleza jurídica del empleo en casas particulares: la destinataria de los servicios, entendida como familia o vida familiar.

Palabras clave: empleo doméstico, violencias, familia, derecho laboral, feminismos.

* Doctora en Ciencias Sociales de la Universidad de Buenos Aires. Investigadora del Consejo Nacional de Investigaciones Científicas y Técnicas (Conicet), Universidad Nacional de Córdoba (Argentina). Correo electrónico: rclerussi77@gmail.com 


\section{ABSTRACT}

The March 13, 2013 was approved in Argentina the "Special Regimen of Work Contract for Personal Private Houses". This standard abrogated the previous Decree 326/1956, which for over fifty years and sanctioned in the context of military dictatorship, had regulated the domestic sector under conditions that have been considered not only discriminatory but also unconstitutional. From a feminist legal perspective, the general hypothesis we support is that despite having a new regulation, the problems associated with such modalities of structural labor violence as exclusion, inequality, invisibility and the historic undervaluation given to this feminized work, will not be solved only with a new law (which, however, we celebrate), but with radical interpretations of what the dogmatic called "legal nature" of this sector. Under this hypothesis, in this article we concentrate on one of the three elements of the "legal nature" of domestic work: the recipient of the services understood as family or family life.

Keywords: domestic employment, violence, family, Labour Law, feminism.

\section{RESUMO}

O 13 de março de 2013 foi aprovado na Argentina o Regime especial de contrato de trabalho para o pessoal de casas particulares. Esta norma derrogou o Decreto Lei 326/1956, o qual foi sancionado em um contexto de ditadura militar e regulou por mais de 50 anos ao setor doméstico em umas condições que têm sido qualificadas não só de discriminatórias, mas também inconstitucionais. Situadas no pensamento jurídico feminista crítico, a hipótese geral que sustentamos é que, apesar de contar com uma nova regulação, os problemas associados com modalidades de violência laboral estrutural tais como as exclusões e desigualdades. A invisibilidade e infravaloração históricas dadas a este setor laboral feminizado não se resolvem só com uma nova lei (que, no entanto, celebramos), mas com disrupções e deslocamentos radicais nas interpretações do que a dogmática entende por sua natureza jurídica. Com esta hipótese, no presente texto abocamo-nos a uma das três notas definidoras da natureza jurídica do emprego em casas particulares: a destinatária dos serviços, entendida como família ou vida familiar.

Palavras-chave: emprego doméstico, violências, família, direito laboral, feminismos. 


\section{Introducción}

El 13 de marzo de 2013 fue aprobada por el Congreso argentino la Ley 26844 que crea el Régimen especial de contrato de trabajo para el personal de casas particulares. Esta norma derogó a la anterior, el Decreto-ley 326 de 1956, sancionado en un contexto de dictadura militar que reguló por más de cincuenta años al sector doméstico en unas condiciones que han sido calificadas no solo de discriminatorias, sino inconstitucionales (Capón, 2000). ${ }^{1}$

A partir de entender que los elementos esenciales del contrato de trabajo doméstico son los mismos que los existentes en un contrato de trabajo típico (dependencia-subordinación; prestación personal o infungible; remuneración o contraprestación; autonomía de la voluntad de las partes) (El Hay, 2013; Ocampo, 2013), la nueva normativa sigue el criterio de estatuto mínimo, similar al de otros colectivos laborales como el trabajo a domicilio y el trabajo rural. Este tipo de estatutos tiene como presupuesto básico el reconocimiento de que la especialidad de un sector que justifica una regulación normativa diferenciada no obsta a la aplicación de la Ley de contrato de trabajo (o Régimen de contrato de trabajo) en tanto Derecho Laboral común para todos los trabajadores y las trabajadoras del sector privado (Ruiz, 2013). Es decir, por un lado, la nueva Ley reconoce derechos fundamentales para el sector, con lo que mejora las condiciones laborales y, por el otro, establece una relación supletoria respecto a la Ley de contrato de trabajo (LCT) bajo determinadas circunstancias y en todo cuanto no se oponga a su régimen específico. A ello se suma el marco general de principios de interpretación y aplicación ya existentes: los de justicia social, los generales del derecho, la equidad y la buena fe.

El reconocimiento de una base regulatoria común y general encarnada en el Régimen de contrato de trabajo (con el gesto de la supletoriedad en ciertos estatutos especiales, como el caso en cuestión) parte de la necesidad

En el presente texto usamos indistintamente el término sector doméstico y sector de casas particulares, sin desmerecer en lo absoluto el salto semántico que se produce entre el primero y el segundo. Utilizamos la palabra doméstico como derivada del latín domus en la denominación perteneciente a la casa, acepción asumida también por la Organización Internacional del Trabajo (OIT) en el Convenio 189 de 2011, cuando alude al trabajo doméstico como aquel realizado en un hogar u hogares o para los mismos. También empleamos los términos régimen de contrato de trabajo; Ley de contrato de trabajo o las siglas LCT para nombrar al régimen laboral común en la Argentina. 
de establecer un piso de derechos indeclinables, igual para todos los trabajadores y las trabajadoras, reconocidos en la LCT (Ojeda, 2013). Además: "[...] permite asegurar a todos que los avances que se vayan produciendo por reformas parciales a la LCT se extiendan también a los trabajadores comprendidos en Estatutos Especiales, por cierto, en la medida de su compatibilidad con los regímenes específicos" (Ruiz, 2013, p. 168). ${ }^{2}$

La sanción del nuevo régimen para este sector se llevó a cabo en el contexto de un proceso de debates y negociaciones nacionales e internacionales tanto en los sectores sindicales del empleo doméstico o de casas particulares, en los Ministerios de Trabajo de diversos países, en la académica feminista y otras áreas sensibles a estos temas, así como también en instancias supranacionales como la Organización Internacional del Trabajo (OIT).

En el año 2011, luego de varias reuniones y consultas, la OIT sancionó el Convenio 189 (OIT, 2011a) y sus Recomendaciones (OIT, 2011b) y, a partir de las ratificaciones de los Estados parte de la OIT, ha repercutido en las nuevas regulaciones estatales más garantistas, como en el caso argentino. Con todo, tanto las nuevas normas internacionales como las nacionales (en América Latina, Uruguay, Costa Rica, Argentina, solo por mencionar algunos países de América Latina que han modificado sus leyes en la materia) significan un salto cualitativo respecto a las precarias $-\mathrm{y}$, en algunos casos, nulas - regulaciones previas, que mejora en términos normativos la situación de este sector laboral y promueve una revalorización y transformación de la imagen del mismo. Todo ello requiere de análisis que puedan dar cuenta de sus continuidades y discontinuidades y de procesos de concientización que traigan aparejados cambios culturales en los que los sectores sociales deberán involucrarse, entre ellos los/las operadores/as jurídicos/as (Terny y Pisarev, 2013).

Aun en este auspicioso marco legal, el empleo doméstico o en casas particulares sigue siendo entendido como excepcional, especial y diferente, asumidos estos términos como exclusión, desigualdad y menos derechos. Esto, a nuestro juicio se traduce en modalidades de violencia laboral,

2 Para profundizar en aspectos críticos relativos a la relación de supletoriedad del Régimen especial de contrato de trabajo para el personal de casas particulares con la LCT, véase El Hay (2013), Maza (2013) y Ojeda (2013). 
dirigidas en especial hacia mujeres trabajadoras, mayoría en este sector. Cabe aclarar que el sector doméstico en Argentina se compone de casi un millón de trabajadores/as, integrado en un $95 \%$ por mujeres, que ocupa como área laboral un 7,4\% de la población económicamente activa (El Hay, 2013; Terny y Pisarev, 2013).

Según estudios comparados en Europa y América Latina (OIT, 2009), este sector posee regulaciones específicas en muchos casos de carácter discriminatorio respecto al resto de los empleos y se trata de uno de los grupos con mayores índices de informalidad, precariedad y vulnerabilidad, lo que trae aparejada su subvaloración jurídica, sociocultural y económica. ${ }^{3}$ Se trata de "la actividad con mayor proporción de trabajo clandestino y la que concentra mayor cantidad de relaciones laborales sin registrar, grado inusual de incumplimiento que puede fácilmente trasladarse al resto de las obligaciones patronales" (Orsini, 2013, p. 130). Entre los motivos que sustentan tal caracterización de un sector históricamente postergado podemos encontrar: la invisibilización y no valoración del trabajo doméstico no remunerado que se extiende al sector doméstico remunerado; su origen esclavista, colonialista y de vasallaje; el ámbito privado-íntimo en donde se realiza; la dispersión o falta de aglutinamiento del personal en un mismo lugar de trabajo; las dificultades para la organización sindical; la especial característica del sujeto empleador; la falta de valoración adecuada de las tareas desempeñadas por considerarlas, en forma errónea, carentes de valor productivo; la feminización que ha asumido tal tipo de tareas no solo en términos cuantitativos (mayoría mujeres), sino cualitativos (lo que hacen las mujeres y su cadena de significantes atribuidas a lo femenino "vale menos") (Terny y Pisarev, 2013; Ferreirós, 2013; Lerussi, 2014).

La exclusión, particularidad y diferenciación jurídica del empleo doméstico se explica a partir de una serie de consideraciones no manifiestas que articulan aspectos de clases, sexos, etnias y estatus migratorio, entre otras marcas (Pereira y Valiente, 2007). A ello se agrega, en muchos casos, la situación de trabajador/a clandestino/a, es decir, un trabajador negado

3 En términos comparativos, mientras el empleo doméstico en Argentina está registrado apenas en un $15 \%$ (con un $85 \%$ de informalidad), en otros empleos el porcentaje asciende a $71,6 \%$ (con un 28,4\% de informalidad) (Ojeda, 2013). Para conocer las estrategias adelantadas en este país en materia de registración y fiscalización, véase Ruiz (2013). 
por su condición de tal que es puesto indebidamente en una situación de desventaja por un acto ilícito de su empleador (Orsini, 2013).

Se sostiene que las normativas que regulan este empleo están configuradas por un haz heterogéneo y poliforme de regulaciones correspondientes a distintas racionalidades jurídicas, sociales, económicas y políticas tramadas en procesos históricos (Sozzo, 2005). Esto vendría a dar singular forma a este sector y a conformar lo que se entiende por su "naturaleza jurídica". La misma estaría compuesta por tres elementos definitorios: el lugar en donde se hace la prestación (la casa particular, para algunos entendida como hogar), la destinataria de los servicios (familia o vida familiar ajena al trabajador) y la ausencia de ánimo de lucro directo (El Hay, 2013; Ocampo, 2013). ${ }^{4}$ De no presentarse alguno de estos tres elementos, la relación laboral quedaría encuadrada en otro tipo de relación contractual. Esta caracterización no es menor, ya que es la base argumental del Régimen especial (estatuto especial), es decir, la no inclusión en la Ley laboral común (LCT), aun cuando en la nueva regulación se contemple la supletoriedad con la LCT y en un marco jurídico más garantista que el derogado. ${ }^{5}$

En Argentina, en el marco de la nueva regulación para el sector doméstico, han aparecido textos de carácter técnico, que analizan y comentan la nueva ley en cada uno de sus apartados y en relación con el resto de regulaciones afines (Rodríguez Saiach, 2013; Gentile, 2013; Mac Donald, 2013 y Álvarez Chávez, 2013) y, en otros casos, abordajes multidisciplinarios dentro del campo jurídico (Segu, 2013). Son producciones muy valiosas, pero a nuestro juicio, carecen de perspectivas de género y feministas que puedan dar cuenta de las matrices conceptuales que han producido a esta labor como tal en las dinámicas laborales feminizadas en la Argentina como un caso entre tantos.

Situadas en el pensamiento jurídico feminista crítico (Olsen, 1990), la hipótesis general que sostenemos es que a pesar de contar con una nueva regulación, los problemas asociados con modalidades de violencia laboral

4 Por naturaleza jurídica, término usado con frecuencia en la dogmática jurídica, entendemos a un conjunto de propiedades consideradas relevantes y definitorias de un objeto jurídico que se usan para leer relaciones jurídicas dando forma a instituciones y figuras del derecho. En este sentido, sostenemos se trata de una categoría jurídico-política.

5 En la doctrina laboral revisada hay acuerdo general respecto de que estas son las tres notas que definen la naturaleza jurídica de este empleo. Sin embargo, hay autores que hacen énfasis en alguno de estos aspectos. Véase Maza (2013), Duarte (2013) y Ocampo (2013). 
estructural como las exclusiones y desigualdades, la invisibilización y la infravaloración históricas dadas a este sector laboral feminizado no se resuelven solo con una nueva ley (que, no obstante, celebramos), sino con disrupciones y desplazamientos radicales en las interpretaciones de su naturaleza jurídica, en un contexto en el que existen resistencias judiciales a trascender los presupuestos tradicionales (Fredman, 1997). Desde esta hipótesis, en el presente texto nos abocamos a una de las tres notas definitorias de la naturaleza jurídica del empleo en casas particulares: la destinataria de los servicios entendida como familia o vida familiar.

Intuimos que el análisis de la situación argentina puede brindar insumos novedosos para abordar el sector en otros contextos (por ejemplo, el colombiano), de acuerdo con las particularidades jurídico-sociales de cada lugar.

A partir del análisis de las posiciones centrales de la doctrina argentina publicadas desde el año 2013 (fecha de la sanción de la nueva normativa), los siguientes apartados están organizados de la siguiente forma: en primer lugar, hacemos algunas consideraciones generales de la destinataria de los servicios. Luego, nos detenemos en tres aspectos particulares de esta nota respecto a los cuales introducimos algunos problemas y contrapuntos que pueden abonar nuevas interpretaciones jurídicas. El primer aspecto es el carácter especial de la destinataria de los servicios, en particular algunos debates en torno a la figura del empleador. El segundo se relaciona con las particularidades del vínculo laboral, las cuales parecieran dar carácter específico a esta labor, aunque en su especificidad se generen zonas grises que ponen a la parte trabajadora en una situación de vulnerabilidad e incertidumbre jurídicas. Por último, presentamos algunos puntos críticos en torno a los deberes o las obligaciones de la parte trabajadora. En el cierre del artículo, hacemos algunas consideraciones a modo de nuevas provocaciones para la labor jurídica en general y jurídica feminista en particular.

\section{La destinataria de los servicios: aspectos generales}

La doctrina jurídica argentina ha asociado la idea de vida doméstica con las categorías de hogar, familia o vida familiar. Esta articulación semántica puede observarse en la vigente normativa para el sector doméstico, en tanto se refiere a las relaciones laborales que se prestan en las casas particulares o 
en el ámbito de la vida familiar (Poder Legislativo de la República Argentina, 2013, art. 1). En los términos de la doctrina: "[...] la ley hace referencia a las personas físicas que son contratadas para prestar servicios en casas particulares, casas de familia o ámbito doméstico expresiones estas tres que son sinonímicas" (Maza, 2013, p. 29). En otras palabras, el estatuto para el sector en cuestión regula relaciones laborales en las casas particulares, es decir, "el servicio prestado en la casa en el significado de hogar, en suma, el que se realiza en la sede de la vida familiar" (Duarte, 2013, p. 8).

Como indicamos, esta nota constituye uno de los elementos medulares que conforman la argumentación de la exclusión de este empleo de la Ley de contrato de trabajo, cuya especificidad radica en las particularidades del vínculo que se establece en la relación laboral (Lerussi, 2014). Se marcan las diferencias entre la naturaleza de una asociación de personas con finalidad de producir bienes o servicios, por un lado y la de la familia o vida familiar por el otro (El Hay, 2009).

Por dicha razón, se excluyen de su alcance las relaciones de servicio doméstico prestadas por personas emparentadas con el dueño de casa, porque se presuponen vínculos afectivos y de estrecha solidaridad. Así, la Ley enumera a las personas comprendidas en esa exclusión, entre las que se encuentran padres, madres, hijos, hermanos, nietos y las que las leyes o los usos y las costumbres consideren relacionadas en algún grado de parentesco o vínculo de convivencia no laboral con el empleador (Poder Legislativo de la República Argentina, 2013 art. 3, inc. b).

Como podrá observarse, se consideran explícitamente entre los excluidos (elemento ausente en la derogada normativa) los vínculos de convivencia no laboral con el empleador, es decir, aquellas personas que conviven y pueden mantener una relación de amistad o afectiva y que de alguna manera cohabitan, pero no prestan servicios laborales (Duarte, 2013; Ocampo, 2013). ${ }^{6}$ Así, para algunos autores, esta novedad legislativa da la posibilidad para que los jueces, ante un diferendo, evalúen el tipo de relación existente: "[...] ya que es obvio que resulta distinta la colaboración de

6 Entre los excluidos de la regulación para el sector en casas particulares, se mencionan además a profesionales para cuidados de personas que habitan la casa y que lo hacen en carácter exclusivamente terapéutico o para la cual se exige contar con habilitaciones profesionales específicas (Ley 26844, 2013, art. 3, inc. c). Para profundizar en este punto, véase Ocampo (2013) y Duarte (2013). 
alguien que desde antes ha sido incorporado a la familia y luego colabora, de la de quien recibe un trato familiar porque colabora sólo desde el afecto" (Ferreirós, 2013, p. 36).

Acerca de este último punto, existen situaciones que podrían problematizar estas nuevas exclusiones, sobre todo por personas que se insertan en la familia o vida familiar mediante acuerdos informales en los que media relación de amistad o afectiva que responden a racionalidades extrajurídicas como los usos y las costumbres familiares o las prácticas afectivas. Entre tantas, destacamos dos, a modo de ilustración. La primera, muy común en los contextos latinoamericanos, es la existencia de las denominadas "niñas de familia", muchachas indígenas o provenientes de contextos rurales que son "adoptadas" por familias mestizas o blancas para hacer labores en la casa a cambio de "padrinazgo", es decir, "protección de un padrino" a cambio de trabajo doméstico no remunerado, muchas veces de por vida (Hernández, 2008). Estas circunstancias lindan con nuevas modalidades de servidumbre doméstica, bajo el manto de vínculos cuasifamiliares o de relaciones interpersonales que propician estados no solo de altísima vulnerabilidad, sino de ilegalidad.

La segunda situación que introduce problemas a estas exclusiones la tomamos de un fallo de la Cámara Civil y Comercial, del Trabajo y Familia (CCyCTyF) de Cruz del Eje, en la provincia de Córdoba (Argentina). En este caso, una persona se puso en el lugar de una trabajadora doméstica y promovió formal demanda laboral en contra de la sucesión de una mujer fallecida, a quien ubicaba en el lugar de su empleadora; exigía pago por diferentes conceptos, con motivo de la realización de actividades domésticas. ${ }^{7}$ El Tribunal resolvió por la negativa, en razón de la falta de pruebas de la relación laboral y por supuesto vínculo "amoroso homosexual" entre la difunta y la demandante, evento excluido de la regulación (anterior y vigente). En la sentencia puede leerse que, de haber existido tales prestaciones, la causa de las mismas respondía a otras motivaciones.

A nuestro juicio, estas situaciones introducen problemas que deberán ser considerados en la labor judicial frente a las nuevas exclusiones. De

7 Fallo de la Cámara Civil y Comercial, del Trabajo y la Familia (CCyCTyF) de Cruz del Eje del 12 de junio de 2007, Córdoba, Argentina. En autos “G., L. c/ Suc. De A. Owintoniw y otros", $\mathrm{s} /$ demanda Laboral, aporte directo del órgano emisor. 
alguna manera, estas requieren ciertos desplazamientos en los modos de interpretación vigentes en la dogmática laboral en cuanto a los vínculos interpersonales o afectivos como excluidos de esta relación laboral, inquietud que dejamos planteada para retomar en próximas reflexiones.

A continuación nos detenemos en tres aspectos particulares de la destinataria de los servicios: el carácter especial del empleador, consideraciones acerca de las denominadas particularidades del vínculo laboral y aspectos críticos relativos a las obligaciones de la parte trabajadora. Para la elaboración de los siguientes apartados hemos consultado doctrina argentina publicada entre los años 2013 y 2015. La doctrina relevante a los fines del presente texto se encuentra concentrada en el año 2013, fecha de la sanción de la normativa vigente; de los años posteriores se han tomado textos relativos a la reglamentación y aspectos fiscales, de seguridad social y registrales vinculados con el sector. Por lo tanto, las fuentes centrales serán las doctrinarias del año $2013 .{ }^{8}$

\section{Aspectos particulares de la destinataria de los servicios}

\subsection{Carácter especial}

En la doctrina y la literatura jurídica solemos leer con frecuencia que el empleo en casas particulares es un trabajo singular y, por sus características, especial. En parte, estas cualidades son asignadas por la destinataria de los servicios, la familia o vida familiar, distinguible de otros contextos como los empresariales o industriales. Hay un elemento cardinal en el que insiste la doctrina respecto a esta diferenciación, que es la condición singular de la parte empleadora en tanto no empresaria.

Sostenemos que no se trata de negar las diferencias del sector de casas particulares frente al resto de empleos (en principio, todos los empleos son diferentes), sino de mostrar cómo respecto al sector doméstico, el término diferente equivale a especial y por tal, con menos derechos, lo que ubica a este sector en un lugar de desigualdad jurídica.

8 Para conocer las fuentes consultadas, véanse las referencias del presente texto. 
El punto de referencia paradigmático del Derecho del Trabajo fue la empresa como fuente productora de bienes para el mercado (Machado, 2003). Ello hizo que la regulación del empleo doméstico por el Derecho Laboral siempre fuera considerada marginal, en el sentido de que esta relación laboral no forma parte de las típicas relaciones de tipo fabril, industrial o empresarial. Por lo tanto, las tendencias iniciales eran de resistencia para incluirlo en la órbita del Derecho Laboral, pues aunque se tratara de una forma de contrato de trabajo, su desenvolvimiento no afectaba a la vida industrial, ni a las empresas mercantiles y su ejercicio no suponía una actividad económicamente productora, es decir, no se trataba de un contrato de trabajo en sentido estricto (Brito, 1982). Estos supuestos, entre otros, fueron catalogando a este empleo como inferior en términos jurídicos y económicos.

Aun en los nuevos marcos laborales y jurídicos más inclusivos y garantistas respecto al sector en casas particulares, hay una tendencia fuerte a apelar a este tipo de argumentos en los que se insiste en la figura del empleador como un no empresario y al lugar de trabajo como un no establecimiento comercial, cuyo objetivo, al disponer la contratación laboral, no es la obtención de una ganancia económica. Vale mencionar un aspecto relevante y es el hecho de que en la normativa ya derogada que regulaba el sector doméstico (Presidencia de la Nación Argentina, 1956) se enunciaba al empleador como dador de trabajo (distanciado de la LCT), mientras en la nueva normativa (Ley 26844, 2013) se ha dado un salto cualitativo y se denomina "empleador", sin más. Así, se entiende técnica y jurídicamente por tal a todo aquel que contrate personal doméstico (García, 2013; Pasini, 2013).

En el contexto de los debates doctrinarios en torno a la normativa vigente, un autor que ha insistido en la diferenciación empleador-empresario es Maza (2013). Aunque reconoce a la nueva regulación como muy positiva, el doctrinario acentúa aspectos relativos a la naturaleza no empresarial de los empleadores del sector doméstico y expone una crítica fuerte a la equiparación del régimen reparatorio del despido sin causa justa entre el Estatuto particular vigente (Ley 26844) y la ley general (LCT). Maza (2013) sostiene: “[...] creo errado imponer una idéntica $-y$ prescindo para esto de 
la supresión del tope salarial- carga patrimonial frente al despido injustificado a una organización empresarial y a un dueño de casa o una familia" (p. 36). A continuación nos centramos en su argumentación.

En primer lugar, considera la equiparación en el punto indicado como una decisión política no acertada e incluso no racional, ya que en el sector en cuestión el empleador no es un empresario (como el que tiene en cuenta la LCT) y con frecuencia es otro trabajador dependiente. En palabras de Maza (2013): "[...] luce incorrecto que un empleador y una unidad familiar, con tal disímiles capacidades y poderes económicos, sean tratados por la ley como iguales cuando son tan distintos" (p. 37). Es decir, el costo económico que supone enfrentar una indemnización por despido injustificado difiere considerablemente entre un empresario y un empleador de casas particulares. En sus términos:

[...] el empleador doméstico -que en un altísimo número de casos del mundo actual es otro empleado dependiente, o un matrimonio de empleados dependientes, o un trabajador cuentapropista- no está en condiciones, como regla general, de trasladar ese costo familiar a sus ingresos porque carece de ese poder o facultad (Maza, 2013, p. 36).

En segundo lugar, el empleador (no empresario) no contrata a un trabajador doméstico para producir bienes o prestar servicios, sino para su consumo personal en el ámbito civil del hogar, para la satisfacción de necesidades propias o familiares (Maza, 2013).

A estos dos argumentos, el propio autor contrapone una réplica posible que puede imponerse y es el planteo constitucional de que todos los trabajadores dependientes deben ser protegidos de la misma manera por la ley frente al despido injustificado, pues ante esta todos los dependientes son iguales. Maza responde con el Artículo 14 bis de la Constitución nacional argentina y recurre a la inexistencia de un deber de uniformidad protectoria. Según este autor, de la propia Carta Magna puede afirmarse que "es válido y razonable dar diferentes niveles o intensidades de beneficios a trabajadores dependientes por diversos motivos que el Congreso deberá evaluar" (Maza, 2013, p. 37). Dicho en otras palabras, sería válido jurídicamente seguir criterios diferentes según las peculiaridades de cada caso o sector laboral. Luego, el mencionado autor presenta algunos ejemplos 
en tal sentido y vuelve a la tesis central respecto a su desacuerdo con la equiparación entre el régimen especial vigente y la ley en cuanto al trato por despido injustificado.

A continuación presentamos algunos contraargumentos. En primer lugar, sobre la cadena de equivalencias empleador-empresario, el doctrinario Capón Filas (2000), desde hace más de dos décadas, viene afirmando que quienes sostienen posturas bajo el supuesto no empresa del empleo doméstico se centran en que quien recibe el trabajo no es empresario, de donde se presupone una coincidencia natural entre la figura del empresario y la del empleador. Según Capón Filas (2000) esta tesis:

[...] identifica empresario con empleador, como si los únicos empleadores fuesen los primeros. De este modo, [...] no advierten que el empleador puede no ser empresario en sentido económico-funcional del término, [es decir], esta coincidencia puede a veces faltar, ya que hay empleadores que no son empresarios [quien emplea a un trabajador domésticol o a la inversa, empresarios que no son empleadores porque no emplean a ningún dependiente (pp. 789-790).

Situación que, agrega el autor, se observa con frecuencia en los contextos laborales actuales, sobre todo en el sector de los servicios. Igual postura encontramos en la doctrina actual referida al sector donde se afirma: "[...] sabemos que empleador es quien requiere los servicios de un trabajador, que trabajador es quien presta ese servicio, bajo la dependencia de aquel, mediante el pago de una remuneración, y que no todo empleador es un empresario" (Salvatierra, 2013, p. 239).

Por tales motivos, dado el evidente equívoco entre empresario como equivalente a empleador, no habría razones suficientes para argumentar contra la equiparación entre el sector de casas particulares y la LCT en cuanto al punto controvertido de la indemnización por despido sin causa, en razón de no tratarse de un empresario contratante.

En segundo lugar, el empleador del sector doméstico no contrata personal para producir bienes o prestar servicios destinados a terceras personas, pero sí para producir bienes (por ejemplo, preparar alimentos ingeribles a partir de materias primas) y brindar servicios (por ejemplo, lavado y planchado de ropa) para consumo personal de acuerdo con las 
necesidades individuales o familiares. No está claro el motivo por el cual Maza (2013) introduce este argumento que consideramos equívoco como para sostener la no equiparación del régimen reparatorio por despido sin causa justa. Puesta la falta de claridad de su planteo en este punto, introducimos dos aspectos que, inferimos, pueden estar latiendo en el fondo de sus afirmaciones.

Por un lado, la referencia al ámbito civil del hogar en los términos de dicho autor. Ese ámbito es lugar de trabajo desde el punto de vista de la parte trabajadora; por lo tanto, a los efectos laborales, debería prevalecer el concepto de centro de trabajo sobre el de domicilio. Criterio, vale decir, tomado de la doctrina española (López, 2008), a raíz de la exacerbación del postulado de inviolabilidad del domicilio que restringe las posibilidades de inspección y fiscalización directa por parte de las agencias del Estado en un contexto de sistemáticas violaciones de derechos laborales (OIT, 2009).

Por otro lado, entre las posturas que articulan empleador con empresario, se presupone el argumento relativo al ánimo de lucro. En la normativa vigente del sector se ha avanzado respecto al lucro indirecto. Se afirma:

[...] si el empleador se ocupara de las tareas domésticas debería perder horas de su propio trabajo, con la consecuente disminución de sus ganancias, por lo que también está fuera de discusión que el trabajo doméstico significa un beneficio económico para quien lo recibe, ya que si tales tareas no las hiciera la trabajadora doméstica, debería hacerlas el propio empleador. Esto es lo que se conoce como lucro negativo o indirecto, es decir, lo que no se perdió, en contraposición al lucro o beneficio económico directo, que excluye a los efectos de la tipificación de la relación, la Ley 26844 (Salvatierra, 2013, p. 239).

Se ha incluido entonces en la nueva norma al lucro indirecto y excluido al lucro directo, aunque en la doctrina hay desacuerdo respecto de este punto. En palabras de El Hay (2013):

[...] al apropiarse de tiempo y de la fuerza de trabajo de la trabajadora doméstica a un costo inferior al que le insumiría dedicar su propio esfuerzo a realizar las tareas que delega a aquélla (perdiendo en tal caso la posibilidad de obtener ganancias superiores al salario que le paga a la empleada) es evidente que existe, aun de modo mediato, un fin de lucro 
en la persona que emplea a una trabajadora doméstica, por lo que el argumento debe ser descartado como base objetiva de diferenciación (p. 225).

A nuestro juicio, lo que se está disputando (sin explicitarlo) es la concepción clásica sobre los trabajos de servicios, según la cual ya que no se producen bienes susceptibles de intercambio - esto es, no producen mercaderías - no son productivos. De alguna manera la consideración de la destinataria de los servicios como un sujeto no empresa pone de manifiesto la cadena de equivalencias dicotómicas en economía que, entre otras, ubican a la empresa o fábrica en el lugar de lo económico y mediada por el dinero y a la familia o vida familiar en tanto no económica y mediada por la afectividad. En línea con Zelizer (2005), dichos términos se modificarían si se pensara en la clave de los procesos de negociación de la intimidad -similares, por cierto, a los del mercado- que surgen en los grupos domésticos, incluidas las familias, en donde también media el dinero, contexto familiar en el que existen múltiples y permanentes conflictos en torno al dinero: acceso, circulación, distribución, significaciones y usos, situaciones de explotación, desigual distribución, extorsiones monetarias, violencias económicas, en fin. Esto tiene particulares consecuencias para el personal contratado en el sector doméstico en lo que hace a los procesos de negociación y significación de la relación laboral y de su contenido económico o salario.

Por último, en cuanto la réplica al igual trato y protección por mandato constitucional de todos los trabajadores dependientes frente al despido injustificado, decimos dos cosas. En primer lugar, no se niega que las unidades de trabajo familiares y las empresariales son diferentes (en principio, todas las unidades de trabajo son diferentes); lo que se afirma es que, con ese argumento, muchas veces se propician situaciones de desigualdad de trato en las relaciones laborales que, a nuestro juicio, son modalidades de violencia laboral. Lo que se discute es la operación articulatoria diferenteespecial que tiene como correlato la desigualdad de trato, operación que no es necesaria, pero sí frecuente, en la doctrina y más aún en el sector laboral en cuestión. Es más, durante mucho tiempo, las denominadas diferencias relevantes de la naturaleza jurídica del sector en casas particulares justificaron un régimen especial discriminatorio; no eran las diferencias formales del vínculo laboral (siempre fue un contrato de trabajo típico), 
sino los elementos retóricos de su naturaleza considerados inequiparables a cualquier otra relación laboral los que primaban para justificar tanto la exclusión de la LCT como su trato desigual (Lerussi, 2014). De ahí que la tendencia del nuevo régimen ha sido la de equiparar en la mayoría de circunstancias, aun con un estatuto mínimo.

En segundo lugar, es importante recordar que entre las posturas asimilacionistas o igualadoras como las de Capón Filas (2000) se afirma, acerca de las posiciones diferencialistas, que entre las argumentaciones jurídicas se sostiene el supuesto riesgo a una agravación de la situación de las economías familiares. Ello derivaría en un considerable incremento en los derechos que los trabajadores domésticos habrían de experimentar si gozaran de un estatuto laboral equivalente al del resto de empleos o si fueran asimilados por la normativa común.

La equiparación frente al despido injustificado ha sido una medida que ha recogido el legislador en Argentina no solo a partir de una posición igualitarista, sino de la realidad misma del sector, en el que los despidos injustificados suelen ser muy comunes y crean situaciones de gran desprotección laboral. Luego, en cuanto a los costos, deberán ser evaluados por el empleador a la hora de la contratación y, además, respecto a sus obligaciones, incluidos los costos del despido, como sucede con el resto de sectores laborales regulados por la LCT bajo la regla general de la uniformidad protectoria, criterio constitucional prevalente en lo laboral.

\section{Particularidades del vínculo}

En la literatura jurídica, es muy frecuente leer que en el curso regular del empleo en casas particulares, se desarrollan vínculos afectivos y por lo tanto, se produce el efecto de crear una comunidad de vida que se deriva de la continuidad y de la convivencia (en la modalidad sin retiro) o por lo menos de la estancia en el hábitat del grupo atendido (Lavín, 2006). De ello suele inferirse que en estas relaciones predominan normas familiares que garantizan la normal y armónica convivencia entre las partes. De allí las supuestas características singulares de este trabajo, dadas por la destinataria de los servicios.

Suele destacarse que se trata de trabajadores de confianza con quienes muchas veces se establecen relaciones cuasifamiliares o filoafectivas. Por 
dichos motivos, entre otros, es frecuente observar las resistencias a regular la relación laboral. Afirma Ojeda (2013):

[...] los empleadores no ven la necesidad de formalizar la relación con el personal del servicio doméstico. Esperan que en el hogar, el intercambio de servicio se produzca por respeto, afecto o sentido del deber, y no sobre la base de una relación contractual. Así, habitualmente, la esfera privada se considera ajena a la lógica mercantilista del mercado de trabajo y a la vigilancia del Estado (p. 53).

Cabe mencionar cuatro cuestiones preliminares. La primera es que, bajo el efecto de dichos supuestos, se tiende a borrar o a crear zonas de ambigüedad en la relación laboral que, al menos en términos objetivos, no son favorables para la parte trabajadora desde el punto de vista de la protección y garantía de sus derechos. En segundo lugar, se tiende a presuponer que la familia es un espacio armónico y afectuoso, cuando muchas veces es un espacio de disputas, coerción y violencias (Fraser, 1986), contexto en donde se inserta el personal de casas particulares y que se configura en su lugar de trabajo (y de vida, en el caso del personal sin retiro). Por ello, el sentido de comunidad familiar se complejiza, al involucrar al personal en dinámicas que le son ajenas (aspecto acentuado en el caso del personal sin retiro) y a veces hasta violatorias de sus derechos. En tercer lugar, para marcar la singularidad de la destinataria de los servicios del sector en casas particulares, al supuesto de la afectividad y solidaridad de las relaciones familiares suelen contraponerse los intereses y el egoísmo que se supone median las relaciones comerciales. Como ya insinuamos, se trata de una falsa dicotomía, ya que ni las familias son per se comunidades solidarias y afectuosas ni en las empresas se dan per se relaciones egoístas por mediación del dinero (Zelizer, 2005). En cuarto lugar, observamos que ciertas características atribuidas desde la dogmática laboral al sector en cuestión (a las referidas agregamos la reciprocidad, el respeto, la cordialidad, la responsabilidad) son o deberían ser comunes a todo contrato de trabajo: "[...] ni la fábrica excluye el deber de comportarse como buena persona, ni el hogar debe hacer olvidar que se trabaja por salario" (Machado, 2003, p. 14). Por lo tanto, no habría ninguna razón para considerar esas cualidades como propias del empleo en casas particulares y, en caso de entenderlas 
como implícitas, no lo son solo para este sector, sino para todas las relaciones laborales.

A continuación nos detenemos en un punto de la nueva regulación: el período de prueba, que arrastra un problema estructural que comparte con la LCT (Duarte, 2013) y es su propia definición, porque puede propiciar situaciones de arbitrariedad (con argumentos basados en las particularidades del vínculo laboral) que se condicen con principios constitucionales.

El nuevo régimen para el sector en cuestión ha recogido el principio de indeterminación del contrato y dispuesto un período de prueba con algunas diferencias respecto al régimen general (LCT). El Artículo 7 establece un período de prueba de treinta días para el personal sin retiro y de los primeros quince días de trabajo, en tanto no supere los tres meses, para el personal con retiro. En tales casos, la Ley establece que cualquiera de las partes podrá extinguir la relación durante ese lapso sin expresión de causa y sin generarse derecho a indemnización con motivo de la extinción. La norma agrega que el empleador no podrá contratar a un mismo empleado más de una vez utilizando el período de prueba.

Haremos tres consideraciones: una general, en línea con Duarte (2013) y referida al uso del término período de prueba en la legislación argentina y dos particulares sobre el sector en casas particulares.

En Argentina, lo que legislativamente se denomina período de prueba es, en palabras de Duarte (2013):

[...] una modalidad de contratación con características especiales -como es esta de establecer, con cierta contradicción, un aseguramiento del principio de indeterminación del plazo, con exclusas bien definidas-, pero drenando todas esas garantías, estableciendo una flexibilidad de salida en los primeros tiempos de la relación (p. 25).

Lo que se entiende por período de prueba habilita modalidades de despido arbitrario que se oponen a la Constitución, ya que el despido arbitrario en el período de prueba no reconoce ninguna protección. Según Duarte (2013):

[...] el legislador posibilita reconocer como si fuera una prueba, cuando en realidad se trata de la flexibilidad de entrada al contrato reconocida 
legalmente (con fuertes sospechas de inconstitucionalidad, no solamente en este régimen, sino también el consagrado en el art. 92 bis de la LCT) porque se permite romper el vínculo sin ninguna exigencia al empleador acerca de la idoneidad del trabajador para reconocer que efectivamente se trató de un período en el cual el trabajador se encuentra a prueba y se acepta que no cumplió con el objetivo sin ninguna carga para el empleador, frente a la exigencia del artículo 14 bis de la Constitución Nacional sobre despido arbitrario, y la única distinción en los empleos es la idoneidad (art. 16 de la Constitución Nacional) (p. 25).

Por lo tanto, podría decirse que se trata de un mal llamado período de prueba que encubre la flexibilidad inicial del contrato y que puede ser objeto de arbitrariedad o fraude, ya que las partes pueden extinguir la relación laboral en el lapso, sin generar derecho a indemnización con motivo de la extinción. Sabemos que en esos casos la parte trabajadora es la que más requiere protección.

Lo anterior tiene consecuencias atendibles en el sector doméstico. Por una parte, al suponerse que se trata de vínculos mediados por la afectividad que con frecuencia generan zonas grises en la relación laboral, lo que se espera del personal es eso: empatía, afectividad y recursos emocionales varios. Estas cualidades no deberían ser, desde un punto de vista jurídico, las definitorias en cuanto a la idoneidad para dar curso a una relación laboral o suspenderla dentro del denominado período de prueba. Aún más cuando se trata de un sector en donde hay frecuentes rotaciones de personal con base en que "los vínculos personales son más estrechos y los gustos y preferencias se acentúan cuando se trata de incorporar personas ajenas al hogar" (Duarte, 2013, p. 26). Gustos, preferencias, vínculos afectivos son elementos que adolecen de un criterio objetivo en la definición de la idoneidad, por lo que pueden ser causa de arbitrariedad y dejar a la parte trabajadora en una situación de gran vulnerabilidad (en particular, para el personal sin retiro, que muchas veces se desplaza de otra ciudad o país). Por lo tanto, este sector requiere enfáticamente la protección jurídica de la cual gozan todos los sectores laborales, más en el marco de la amplia flexibilidad que habilita la Ley para el sector doméstico y que debería ser observada por los mecanismos de control del Estado. Asimismo, deberían hacerse distinciones entre quienes contratan a una persona y quienes contratan 
varios trabajadores domésticos y en diferentes categorías profesionales, caso en el que la flexibilidad debería ser restringida para resguardar de posibles fraudes a la parte trabajadora (Duarte, 2013).

Para evitar formas abusivas en el uso del período de prueba y situaciones violatorias de derechos laborales, es fundamental fomentar el registro progresivo (recordemos que en Argentina hay un $85 \%$ de informalidad en el sector) y generar mecanismos ágiles de fiscalización, control e inspección por parte de los órganos del Estado, algunos de los cuales ya están previstos en la nueva reglamentación (2014). ${ }^{9}$

\section{Deberes de la parte trabajadora}

En el Artículo 14.2 de la regulación vigente se establecen los deberes exigibles a la parte trabajadora, a saber: cumplir las instrucciones de servicio que se le impartan; cuidar las cosas confiadas a su vigilancia y diligencia; observar prescindencia y reserva en los asuntos de la casa de los que tenga conocimiento en el ejercicio de sus funciones; preservar la inviolabilidad del secreto personal y familiar en materia política, moral, religiosa y en las demás cuestiones que hagan a la vida privada e intimidad de quienes habiten la casa en donde se presten servicios y desempeñar sus funciones con diligencia y colaboración. Se entiende que dichos deberes se fundan en las peculiaridades de este empleo prestado en la intimidad de la casa particular o en el ambiente familiar y, por este motivo, se ha llegado a sostener que se debe exigir un mayor deber de obrar con prudencia, cuidado, diligencia y colaboración (Lavín, 2006). En el marco de la nueva normativa, encontramos posiciones como la siguiente:

La dignidad del hombre tiene amplia recepción en los art. 4, 66 y 68 de la LCT aplicables a este régimen [Ley 26844] y, el campo de acción del empleador está dado por la diligencia exigible a un buen padre de familia que crea en el caso de deberes particulares, pues hay una vinculación especial sellada por la confianza y el respeto entre las personas que interactúan en el hogar. La diligencia que se requiere a un buen padre de familia cobra sentido especial en este ámbito, pues no se trata de llevar

9 Para conocer aspectos de la reglamentación relativos al registro y a la documentación, véase Lodi-Fe (2014), Almendra (2014) y Anunziato (2015). 
adelante un negocio sino de conducir al grupo familiar al que está estrechamente ligado el empleado de la casa [...]. Los derechos y deberes de estos empleados deben ejercerse y cumplirse de acuerdo con las pautas de buena fe y solidaridad que establecen los artículos 62 y 63 de la LCT adquiriendo singular relevancia la discreción y la fidelidad del empleado y, por parte del empleador, el trato respetuoso y considerado (Fernández, 2013, p. 261).

En similar sentido y desde doctrina vigente, después de hacer mención a los deberes de la parte trabajadora como están enunciados en la ley, Pasini (2013) sostiene que "las obligaciones referidas se encuentran relacionadas con el deber de fidelidad del trabajador para con el empleador" (p. 72).

A continuación hacemos algunas consideraciones críticas relativas a ciertos aspectos de los deberes de la parte trabajadora. Partimos de entender que el cuidado, la buena conducta y la discreción deberían ser características de todas las relaciones laborales y no más relevantes para nuestro caso; luego, claro está, se puede discutir qué se entiende por cuidado, buena conducta y discreción, pero en tanto deberes comunes a todos los trabajadores y no más atendibles en el sector de casas particulares.

En cuanto a la exigencia de preservar la inviolabilidad del secreto familiar y personal, en la dogmática laboral encontramos que los motivos de ese deber se fundan en los siguientes argumentos: la convivencia (parcial o total); la mayor intimidad de la relación dada por el espacio físico en donde se ejerce la actividad; la confidencialidad de los vínculos que pueden generarse en razón de la destinataria de los servicios (familia o vida familiar); el acceso al conocimiento de las conductas y opiniones de quienes habitan en la casa, sea empleador o terceras personas en carácter de visitantes, incluidos aspectos asociados con la crianza y educación de los niños (en el caso de las cuidadoras remuneradas, también llamadas "niñeras"); el conocimiento de bienes o cosas de diverso valor y origen de la casa particular. Cada uno de estos supuestos presenta una serie de derivas que, de transgredirse, la relación laboral podría estar en riesgo; es más, el deber de preservar el secreto familiar llega muchas veces a imponer conductas al trabajador por fuera de su lugar y horario de trabajo. Aunque se reconoce que se trata de una regulación de los deberes del trabajador, se considera que su trasgresión afecta la imagen de la familia a cuyo servicio se encuentra afectado 
(Reviriego, 1999). Esto puede acarrear serias consecuencias desde el punto de vista de los derechos de la parte trabajadora (sobre todo para el personal sin retiro), en especial frente a su derecho a la intimidad.

En cuanto al deber de fidelidad, no por casualidad esta obligación presente en la derogada normativa no ha sido recogida en la ley vigente. Se han considerado directrices tanto de la normativa internacional emanada de la OIT como de los tratados de rango constitucional (Corte Suprema de Justicia de la Nación, art. 75, inc. 22). Sin embargo, observamos que, contra legem, este deber es enunciado de manera explícita en cierta doctrina. Entendemos que se trata de una operación retórica que, a modo de síntoma, visibiliza algunas continuidades entre la antigua y la nueva normativa que podrían seguir operando a modo de fantasmas en supuestos jurídicos actuales. Esta conjetura, claro está, no opera como inferencia necesaria, sino a modo de vigilancia epistémica y legal.

\section{Consideraciones finales}

Hemos presentado diferentes aspectos críticos referidos a la destinataria de los servicios del sector en casas particulares, la familia o vida familiar, a partir de analizar los argumentos centrales dados por la doctrina laboral argentina publicada desde 2013 (año de sanción de la nueva normativa). En primer lugar y en el abordaje de aspectos generales de la destinataria de los servicios, nos detuvimos en ciertos problemas que podrían presentarse respecto a las nuevas exclusiones que especifica la normativa vigente. Por una parte, el caso de relaciones interpersonales en donde pueden convivir vínculos mixtos laborales y afectivos (tema que no excluye la revisión de los denominados deberes u obligaciones maritales o de las uniones convivenciales). Por otra parte, situaciones muy comunes en nuestros contextos de incorporación a la unidad familiar de personas en carácter de invitadas (por ejemplo, las llamadas "niñas de familia", muchachas indígenas o de procedencia rural que son "adoptadas" por familias mestizas o blancas), que muchas veces hacen labores domésticas como intercambio, sin una configuración laboral adecuada, lo cual genera situaciones de alta desprotección y, en algunos casos, de ilicitud. 
Luego, expusimos tres puntos específicos de la destinataria de los servicios. Introdujimos, en una primera instancia, problemas referidos a su supuesto carácter especial, específicamente acerca de la figura del empleador como no empresario. Expresamos algunas críticas y contrapuntos que, a nuestro juicio, despejan por completo este equívoco, sobre todo ante la equiparación del régimen reparatorio del despido sin causa justa entre el Estatuto particular vigente y la Ley general (LCT), como parte de una normativa de tendencia igualitarista, garantista y protectora.

Acerca del segundo aspecto específico que presentamos bajo el título "Particularidades del vínculo", expusimos una serie de consideraciones en relación con la destinataria de los servicios (afectividad, armonía, no violencia, solidaridad, etc.) que, de alguna manera, alcanzan al personal de casas particulares. Ello crea muchas veces un halo cuasiafectivo familiar que tiende a borrar el nexo laboral y crea un sinnúmero de problemas, por ejemplo, las resistencias a la regularización con todo lo que ello acarrea (formalización, registro, fiscalización). Nos detuvimos en el período de prueba, no solo en referencia a ciertos conflictos de tipo conceptual y estructural en la legislación argentina que encubren la flexibilidad inicial del contrato (tema que no abordamos en profundidad en el presente texto), sino que afectan muy especialmente al sector en cuestión, con motivo de esas zonas grises o de ambigüedad creadas por los argumentos en torno a la destinataria. Vimos que se trata de un sector en el que existe una gran rotación de personal, por criterios de valoración que son subjetivos (gustos, preferencias, emociones, etc.), lo que puede ser causa de arbitrariedad y ubica a la parte trabajadora en un estado de gran incertidumbre. Frente a lo expuesto, hemos sostenido que este sector requiere enfáticamente de la protección jurídica de la cual gozan todos los sectores laborales en lo que concierne al período de prueba.

Como tercer aspecto específico de la destinataria de los servicios, nos detuvimos en los deberes o las obligaciones de la parte trabajadora, con énfasis en el deber de secreto familiar; introdujimos algunas consideraciones concernientes al derecho a la intimidad de la parte trabajadora que deben ser asumidas con mucho cuidado. En cuanto al ya derogado deber de fidelidad, hicimos algunos comentarios - no sin sospechas- de continuidad en las tramas interpretativas actuales, a las cuales habrá que prestarles especial atención. 
A nuestro juicio, los problemas referidos a la destinataria de los servicios, la familia o vida familiar, tienen implicancia no solo en la especificidad de un sector laboral; es menester comprender que esta concepción del trabajo doméstico remunerado y de su naturaleza jurídica no es puntual o esporádica, sino que viene de las asunciones que se tiene del trabajo doméstico no remunerado en todo el sistema jurídico (por ejemplo, respecto a las compensaciones económicas para las mujeres, que deberían generarse con motivo de divorcio o suspensión de la unión convivencial). De allí la responsabilidad de los actores legales por comprender las implicancias de sus decisiones, puesto que perpetúan el estatus vulnerable de aquellas personas que trabajan con y sin obtener un salario por un trabajo doméstico (Silbaugh, 1996). Dicho en otros términos:

[...] el trabajo doméstico remunerado es tratado de una manera que lo acerca mucho más al trabajo doméstico no remunerado que a cualquier otro tipo de trabajo pago; y su tratamiento refuerza el argumento de que la influencia que tiene cada doctrina legal que devalúa el trabajo doméstico es potenciada por su repetición a lo largo de todo el sistema legal (Silbaugh, 1996, p. 127).

Sin lugar a dudas la nueva regulación argentina para el sector en casas particulares es un gran logro. Sin embargo, aún es largo el camino que queda en cuanto a la difusión, al reconocimiento y a la transformación que este nuevo paradigma requiere para su aceptación y cumplimiento por parte de la población (García, 2013). Entendemos que el Derecho no puede ser solo un instrumento de cambio social en cuanto a la técnica jurídica (leyes, reglamentaciones, procedimientos), sino que también debe ser fuente de producción de conceptos y argumentos que permitan desmontar las matrices que configuran a esta modalidad de trabajo como un empleo infravalorado e invisibilizado, cualidades presentadas en este texto como síntomas de violencia laboral.

Además, sostenemos que esta labor teórica, interpretativa y doctrinaria tiene un alcance mayor en todo el sistema legal tanto respecto al trabajo doméstico remunerado y no remunerado, como a otras modalidades laborales en el contexto de las dinámicas de trabajo actuales que dan forma al preocupante fenómeno de la feminización del trabajo. Si lo femenino en 
el actual sistema de valores es lo que "vale menos", la feminización laboral no es más que un nombre para designar la precarización del trabajo en todas sus formas.

\section{Referencias}

Almendra, G. (2013). Programa de simplificación y unificación registral. Cuestiones prácticas de la implementación del nuevo régimen. En G. Segu (ed.), Nuevo régimen de casas particulares, pp. 297-313. Buenos Aires: Errepar.

Álvarez Chávez, V. (2013). Nuevo régimen del servicio doméstico. Ley 26844. Buenos Aires: García Alonso.

Anunziato, L. (marzo, 2015). Personal de casas particulares: últimas modificaciones mediante las resoluciones (MTESS) 1062/2014, (AFIP) 3653 y (SRT) 2224/2014 y concordantes. Temas de Derecho Laboral, I(3), pp. 45-49.

Brito Peret, J. (1982). Personal que presta servicios en casas de familia. En A. Vázquez Vialard (ed.), Tratado de Derecho del Trabajo, t. 6, pp. 1124-1187. Buenos Aires: Astrea.

Capón Filas, R. (abril, 2000). Servicio doméstico y Mercosur. Revista Derecho del Trabajo, 2000 A, $L X(4)$, pp. 788-794.

Corte Suprema de Justicia de la Nación [CSJN]. (1994). Constitución de la Nación Argentina. Recuperado de http://bibliotecadigital.csjn.gov.ar/Constitucion-dela-Nacion-Argentina-Publicacion-del-Bicent.pdf

Duarte, D. (2013). Un cambio relevante y necesario para el personal de casas particulares. A propósito del Nuevo Régimen Especial de Contrato de Trabajo para el Personal de Casas Particulares. En G. Segu (coord.), Nuevo régimen de Casas Particulares. Ley 26844. Análisis integral multidisciplinario, pp. 3-30. Buenos Aires: Errepar.

El Hay, N. (2009). Jornada de trabajo del servicio doméstico. Córdoba: Advocatus.

El Hay, N. (2013). Derechos del personal de casas particulares a partir de abril de 2013. Revista de Derecho Laboral 2, pp. 217-239.

Fernández Madrid, J. (2013). El principio protectorio, la confianza y la discreción en el Estatuto de empleados de casas particulares. En G. Segu (coord.), Nuevo régimen de casas particulares. Ley 26844. Análisis integral multidisciplinario, pp. 259-265. Buenos Aires: Errepar.

Ferreirós, M. (2013). Ley 26844. Nuevo régimen especial de contrato de trabajo para el personal de casas particulares que desplaza al estatuto de servicio 
doméstico del año 1956. En G. Segu (coord.), Nuevo régimen de casas particulares. Ley 26844. Análisis integral multidisciplinario, pp. 31-58. Buenos Aires: Errepar.

Fraser, N. (1986). ¿Qué tiene de crítica la teoría crítica? Habermas y la cuestión del género. En S. Benhabib y D. Cornell (eds.), Teoría feminista y teoría crítica. Ensayos sobre la política de género en las sociedades de capitalismo tardio, pp. 49-88. Valencia: Ediciones Alfons El Magnanim.

Fredman, S. (1997). Desventaja estructural. En N. Gherardi (comp.), Justicia, género y trabajo, pp. 63-121. Argentina: Libraria.

García Vior, A. (noviembre, 2013). Aspectos estructurales del contrato de trabajo en casas particulares. Ley 26844. A las cosas por su nombre: el empleador doméstico. Doctrina Laboral Errepar, XXVII, 1-42.

Gentile, E. (2013). Régimen laboral para el Personal de Casas particulares. Argentina: Nova Tesis.

Hernández Castillo, R. y Suárez, L. (2008). Feminismos postcoloniales: reflexiones desde el sur del río Bravo. En R. Hernández y L. Suárez (eds.), Descolonizando el feminismo, pp. 75-113. Madrid: Cátedra.

Lerussi, R. (2014). La retórica de la domesticidad. Politica feminista, derecho y empleo doméstico en la Argentina. La Plata: Edulp, Unlp.

Lodi-Fe, M. (agosto, 2014). Personal de casas particulares. Doctrina Laboral Errepar, XXVII, pp. 1-40.

López Gandia, J. (2008), Las relaciones laborales especiales. España: Bomarzo.

Mac Donald, A. (2013), Práctica Servicio Doméstico. Ley 26844 Comentada. Modelos y formularios. Buenos Aires: Eduardo Lecca.

Machado, J. (2003). Acceso al ámbito de protección del decreto 326 /56 para trabajadores del servicio doméstico. Revista de Derecho Laboral, 2, pp. 277-319.

Maza, M. (2013). Elogios y críticas al nuevo régimen de trabajo en casas de familias (Ley 26844). Revista de Derecho Laboral, 2, pp. 27-39.

Ocampo, C. (2013). Ámbito personal de aplicación del nuevo régimen especial de contrato de trabajo para el personal de casas particulares. Posibles alcances de la Ley 26844. Revista Catorce bis, 17XVII(46), pp. 7-13.

Ojeda, R. (2013). Justificación de la Ley 26844. Revista de Derecho Laboral, 2, pp. 41-56.

Olsen, F. (1990). El sexo del derecho. En A. Ruiz (comp.), Identidad femenina y discurso jurídico, pp. 24-43. Buenos Aires: Biblos.

Organización Internacional del Trabajo. (2009). Trabajo decente. Recuperado de http://www.ilo.org/global/topics/decent-work/lang--es/index.htm 
Organización Internacional del Trabajo. (2011a). Convenio 189 sobre el trabajo decente para las trabajadoras y los trabajadores domésticos. Recuperado de http://www. ilo.org/dyn/normlex/en/f?p=1000:12100:0::NO::P12100_ILO_CODE:C189

Organización Internacional del Trabajo. (2011b). Recomendación 201 sobre el trabajo decente para las trabajadoras y los trabajadores domésticos. Recuperado de http:// www.ilo.org/dyn/normlex/en/f?p=1000:12100:0::NO::P12100_INSTRUMENT_ID,P12100_LANG_CODE:2551502

Orsini, J. (2013). Protección del embarazo y la maternidad de las trabajadoras domésticas. Revista Derecho del Trabajo, II(4), pp. 15-154.

Pasini, P. (2013). Régimen Especial de Contrato de Trabajo para el personal de casas particulares. En G. Segu (coord.), Nuevo régimen de Casas Particulares. Ley 26844. Análisis integral multidisciplinario, pp. 59-95. Buenos Aires: Errepar.

Pereira, M. y Valiente, H. (2007). Regímenes jurídicos sobre trabajo doméstico remunerado en los estados del Mercosur. Montevideo: Oxfam.

Poder Legislativo de la República Argentina. (2013). Ley 26.844. Régimen especial de contrato de trabajo para el personal de casas particulares. Buenos Aires: Boletín Oficial, abril 12 de 2013.

Presidencia de la Nación Argentina. (1956). Decreto-ley 326. Régimen de trabajo y previsión del personal que presta servicios en casas de familia. Anales de Legislación Argentina, 16-A, pp. 106-108.

Reviriego, J. (1999). Trabajadores del servicio doméstico. Buenos Aires: Astrea.

Rodríguez Saiach, L. (2013). Personal de casas particulares. Servicio doméstico. Buenos Aires: Gowa.

Ruiz, Á. (2013). El trabajo doméstico frente a la inminente sanción de un nuevo Estatuto legal. Revista de Derecho del Trabajo, 2(4), pp. 165-188.

Salvatierra, C. (2013). La cuestión del tiempo de servicio en el Régimen de trabajadores de casas particulares. En G. Segu (coord.), Nuevo régimen de casas particulares. Ley 26844. Análisis integral multidisciplinario, pp. 237-248. Buenos Aires: Errepar.

Segu, G. (2013). Nuevo régimen de casas particulares. Ley 26844. Análisis integral multidisciplinario. Buenos Aires: Errepar.

Silbaugh, K. (1996). Convirtiendo el trabajo en amor: el trabajo doméstico y el derecho. En N. Gherardi (comp.), Justicia, género y trabajo, pp. 123-174. Buenos Aires: Libraria.

Sozzo, G. (2005). El contrato de servicio doméstico. Itinerario y bifurcaciones. Revista de Derecho Privado y Comunitario, 1, pp. 131-181. 
Terny, L. y Pisarev, A. (2013). El régimen especial de contrato de trabajo para el personal de casas particulares: la creación de una nueva instancia de diálogo social, Revista de Derecho Laboral, 2, pp. 85-103.

Zelizer, V. (2005). La negociación de la intimidad. Buenos Aires: Fondo de Cultura Económica. 